OPEN ACCESS

Edited by: Sidney A. Simon, Duke University, USA

Reviewed by: Sylvia Anton, Institut National de la Recherche Agronomique, France Claude Wicker-Thomas, Centre National de la Recherche

Scientifique, France

Matthew Cobb, University of Manchester, UK

*Correspondence:

Dehbia Abed-Vieillard dehbia.abed@u-bourgogne.fr

Received: 26 October 2015 Accepted: 01 February 2016

Published: 22 February 2016

Citation:

Abed-Vieillard D and Cortot J (2016) When Choice Makes Sense: Menthol Influence on Mating, Oviposition and Fecundity in Drosophila melanogaster.

Front. Integr. Neurosci. 10:5. doi: 10.3389/fnint.2016.00005

\section{When Choice Makes Sense: Menthol Influence on Mating, Oviposition and Fecundity in Drosophila melanogaster}

\author{
Dehbia Abed-Vieillard ${ }^{1,2,3 *}$ and Jérôme Cortot ${ }^{1,2,3}$ \\ 'Centre National de la Recherche Scientifique, UMR6265 Centre des Sciences du Goût et de l'Alimentation, Dijon, France, \\ 2 Institut National de la Recherche Agronomique, UMR1324 Centre des Sciences du Goût et de l'Alimentation, Dijon, \\ France, ${ }^{3}$ UMR Centre des Sciences du Goût et de l'Alimentation, Université de Bourgogne, Dijon, France
}

The environment to which insects have been exposed as larvae and adults can affect subsequent behaviors, such as mating, oviposition, food preference or fitness. Experience can change female preference for oviposition, particularly in phytophagous insects. In Drosophila melanogaster, females avoid laying eggs on menthol rich-food when given the choice. Exposure to menthol during larval development reduces this aversion. However, this observation was not reproduced in the following generation. Recently, we have shown that oviposition-site preference (OSP) differs between wildtype $D$. melanogaster lines freely or forcibly exposed to menthol. After 12 generations, menthol "forced" lines still exhibit a persistent aversion to menthol whereas 'free-choice' lines show a decreased aversion for menthol rich-food. Here, we compare courtship behavior, mating and female fecundity in "forced" and "free-choice" lines, raised either on menthol rich-food (Menthol-lines) or on menthol-free food (Plain-lines). "Forced" males did not discriminate between decapitated virgin females of the two lines. They courted and mated with intact females of both "forced" lines in a comparable rate. However "forced" M-line males did mate significantly more rapidly with "forced" M-line females. In the "free-choice" procedure, P-line males show a similar pattern as "forced" males for discrimination ability and courtship. M-line males courted significantly more M-line females. Both 'free-choice' lines males mated significantly more with females of their own line. Female fecundity was assessed during 10 days in 'free-choice' lines. Mentholline females laid more eggs during the first 4 days than female Plain-lines and parental control-line. The total number of eggs laid during the first 10 days of female adult life is comparable in M-line and parental control line. However, Menthol-line females laid eggs earlier than both parental control and Plain-lines. Our findings show that in D. melanogaster, as for OSP, mating and fecundity are more rapidly influenced when flies have a choice between alternative resources compared to flies permanently exposed to menthol. 


\section{INTRODUCTION}

Choosing a suitable oviposition site is a key decision for egglaying animals such as insects. On this decision depend the survival and even the fitness of the future generation. This is particularly important for animals that remain in the vicinity of or/and feed on the oviposition sites. Numerous factors can affect female decision: food quality and abundance, density of eggs, eggs load, age (Minkenberg et al., 1992 and reference therein), presence of predators, surrounding vegetation, chemical cues of conspecifics (Bentley and Day, 1989; Mokany and Shine, 2003), social learning (Sarin and Dukas, 2009), or prior experience with plants or plant stimuli (Papaj and Prokopy, 1989). Flies are able to oviposit on a wide range of fruits (Atkinson and Shorrocks, 1977) and host selection can be a genetically complex phenomenon (Jaenike, 1986). In Drosophila melanogaster, female oviposition preference can be influenced by social composition, exposure to temperature, surface texture or color of the substrate (Volpe et al., 1967; Fogleman, 1979; Takamura and Fuyama, 1980; Battesti et al., 2015). Similarly, prior exposure to particular food or compounds can also influence female choice (Jaenike, 1983; Abed-Vieillard et al., 2014; Flaven-Pouchon et al., 2014). Exposure to a particular odor can enhance the preference or reduce the aversion to other odors, referred by Jaenike (1983) as cross-induction (Barron and Corbet, 2000). Selection studies on behavioral traits such as oviposition or mating had been conducted. Fogleman (1979) failed to establish strains for low and high temperature preference for oviposition after eight generations. Artificial selection on grape or quince for oviposition site preference did not induce a change in preference in D. melanogaster (Soto et al., 2014). Flies forcibly raised on menthol-rich food for more than 30 generations did not change their aversion to this compound. However, aversion to lay eggs on menthol-rich food can significantly decrease after only 12 generations in free-choice line flies (Abed-Vieillard et al., 2014). These results show that the nature of the compound is an important factor for selection (Jaenike, 1983).

Speciation in phytophagous insects and particularly in the Drosophila group has been intensively studied (Coyne and Orr, 2004; Matsubayashi et al., 2010). Adaptation to a new environment or colonization of novel host plants may lead to sexual isolation (Etges, 1990; Feder et al., 1994). Ethological isolation (sexual or behavioral) is one of the reproductive isolation mechanisms in animals, which can be defined as the deviation from random mating in mated individuals, "individuals will avoid mating with those of another strain, race or species" (Gilbert and Starmer, 1985). Besides the genetic background, external factors such as temperature, diet, density or previous experiences, can potentially act on reproductive isolation (Spieth and Ringo, 1983; Sharon et al., 2010; Najarro et al., 2015).

Pre-exposure to peppermint oil or to menthol (its main component) can reduce aversion in adult flies (Thorpe, 1939; Barron and Corbet, 1999a,b, 2000). We recently compared the oviposition site preference of wild-type D. melanogaster lines freely or forcibly exposed to menthol-rich food. After 12 generations, oviposition site preference differs between the two lines (Abed-Vieillard et al., 2014). The aim of this study was to investigate whether menthol can influence mating and fecundity in D. melanogaster by comparing the "free-choice" lines and the "forced" lines. Our results suggest that when females can freely choose between two egg-laying sites, their choice can influence subsequent behaviors in the offspring.

\section{MATERIALS AND METHODS}

\section{Flies}

Wild-type Dijon2000 strain (Di2) D. melanogaster Meigen established in 2000 were used. Flies were raised on a yeastcornmeal-agar medium and kept at $25 \pm 0.5^{\circ} \mathrm{C}$ with $65 \pm 0.5 \%$ humidity in a 12-h light: 12-h dark cycle.

\section{Menthol and Food Preparation}

Plain food (P-Food) and Menthol enriched food (M-Food) diets for adult D. melanogaster were prepared as described in AbedVieillard et al. (2014). A $250 \mathrm{mg} / \mathrm{ml}$ solution was prepared by dissolving menthol (Pure racemic menthol, M0321, TCI, Japan) in $90 \%(\mathrm{v} / \mathrm{v})$ ethanol and kept at $4^{\circ} \mathrm{C}$ until used. Menthol solution was added to fresh lab food $=$ menthol-food or (M-food). Three concentrations of menthol-food $(0.01,0.1$, and $0.5 \%)$ were used. A similar volume of ethanol $(90 \% \mathrm{v} / \mathrm{v})$ was added to the control diet menthol-free food (Plain-food: P-food).

\section{Exposure Procedures}

Even if food enriched with $0.1 \%$ of menthol elicited an aversion, females still laid eggs on it allowing the establishment of menthol lines. "Choice" and "Forced" lines were established as described in Abed-Vieillard et al. (2014). In summary, the "forced" procedure consisted to raise individuals during their complete development, generation after generation, either on $\mathrm{M}$-food ( $0.1 \%$ menthol; Forced M-line) or P-Food (without menthol; Forced P-Line). The "choice" procedure consisted in keeping the progeny left during a dual choice test (P-food versus M-Food) either on Mor on P-food, generation after generation on that food. Parental "control line," strains unexposed to menthol, were kept in similar laboratory conditions.

\section{Behavioral Tests}

All flies were isolated $0-4 \mathrm{~h}$ after emergence under $\mathrm{CO}_{2}$ anesthesia. For courtship tests, male flies held individually and females, held in groups of five, were kept in fresh glass control food vials for 5 days before testing. For oviposition tests, males or females were held in groups of 25 in similar laboratory conditions. All tests were performed in a room at $25^{\circ} \mathrm{C} \pm 0.5 \%$ with $65 \pm 0.5 \%$ humidity.

\section{Oviposition Preference and Survival}

We performed 4-choice tests using 4 egg-laying sites filled respectively with $0,0.01,0.1$, and $0.5 \%$ menthol food. Twenty-five virgin females and 25 males (parental control-line individuals, 4-5-day-old, previously $\mathrm{CO}_{2}$-anesthetized) were introduced in the test device (described by Abed-Vieillard et al., 2014) during $12 \mathrm{~h}$ at $25^{\circ} \mathrm{C}$. The number of eggs laid on each site was counted. In 
order to assess the survival rate, we allowed larvae to fully develop at $25^{\circ} \mathrm{C}$. Adults were counted for each site. Sites with less than 10 eggs were discarded as for $0.5 \%$, menthol concentration where females rarely oviposited. Twenty-three replicates of four-choice oviposition preference tests were performed.

\section{Courtship Assays}

Two kinds of experiments were performed (i) with decapitated females to measure male ability to discriminate between females of $\mathrm{P}$ and $\mathrm{M}$-lines and (ii) with intact females to measure mating success.

\section{Male Discrimination}

Tests were performed using the same protocol as described by Houot et al. (2010). A watch glass was used as courtship observation chamber $(1.6 \mathrm{~cm} \times 1.6 \mathrm{~cm} \times 1.6 \mathrm{~cm})$. Tester males, whose sexual response to target flies was measured, were individually aspirated (without anesthesia) under the observation chamber and let $5 \mathrm{~min}$ to habituate. Two female target flies (one female for each line) were introduced and the $10 \mathrm{~min}$ observation period started. To distinguish females, one millimeter at the end of a wing of one of the females was cut. To characterize male discrimination, we measured the proportion of time spent by tester males in actively courting (wing vibration, licking, and attempting copulation; total = courtship index, CI) each target female. For each male, we obtained two values corresponding to the CI directed to each target female (CIP: CI for female of the P-Line and CIM: CI for female of the M-line). Tests were carried out under a dim red light $(25 \mathrm{~W}$ with a Kodak Safe- Light Filter $\left.\mathrm{n}^{\circ} 1\right)$ to remove all visual stimuli. Target females were decapitated to remove most acoustic and behavioral signals.

\section{Courtship and Mating}

For the mating experiment, each tester male was paired with a virgin female, for at most $1 \mathrm{~h}$. We measured the CI during the first $10 \mathrm{~min}$, the latency to copulate (time in min from the introduction of the female into the chamber until copulation), the duration of copulation (time in min from the copulation onset until disengagement), and the frequency of copulating pairs for each cross combination.

Tests were performed for the forced-lines and the choice-lines. Flies were paired as follows: Male M-Line $\times$ Female M-line; Male M-Line $\times$ Female P-line; Male P-line $\times$ Female P-Line and Male P-Line $\times$ Female M-Line.

\section{Female Fecundity}

Abed-Vieillard et al. (2014) noticed a significant increase of the number of eggs laid by females in the choice-procedure compared to parental control-lines. In this study, female oviposition preference was checked once from day 1 to day 5 . They showed that Choice P-line and M-line females laid 2-4 times more eggs than the Control-lines. In order to assess if this increase reflects an increased fecundity of the choice-lines females, $2012 \mathrm{~h}$ old virgin flies (10 males and 10 females) were introduced in a oviposition test chamber containing two egg-laying sites, one filled by P-Food and one by M-Food. The parental control line was tested in a similar way. Females were allowed to lay eggs for
$24 \mathrm{~h}$. Then the two sites were removed and replaced by new fresh ones. The tests lasted 10 days. Eggs on each site were counted immediately or frozen until counting. At least 10 replicates were made for each line.

\section{Statistics}

All data were transferred to Prism 5.0d (GraphPad) for statistical analysis except for the ANCOVA [XLSTAT 2012 software (Addinsoft, XLSTAT 2012, Data analysis and statistics with Microsoft Excel, Paris, France)]. Pairs of data were analyzed using the Mann-Whitney test (courtship assays) or Wilcoxon signed ranked test (male discrimination). Groups of more than 2 data sets were compared by Kruskal-Wallis (KW) test followed by a Dunn's multiple comparison test. We used an ANCOVA to compare the fecundity of the tree-line females (referred as cumulated number of eggs per day). The number of eggs were considered as dependent variables, whereas «line type $\gg$ (control, P-, M-choice lines) was considered as a qualitative independent variable and $\ll$ day $\gg$ as an independent quantitative variable. When the ANCOVA result was significant, we used the Tukey test to compare food type effect.

\section{RESULTS}

\section{Oviposition Site Preference}

Female oviposition preference response to menthol-rich media were inversely correlated to menthol concentration $\left(K_{3}\right.$ df $\left.=54.76, p<0.0001\right)$ (Figure 1). D. melanogaster females laid eggs in a similar way in menthol-free and $0.01 \%$ menthol enriched food ( $55 \%$ over $46 \%$ respectively). When

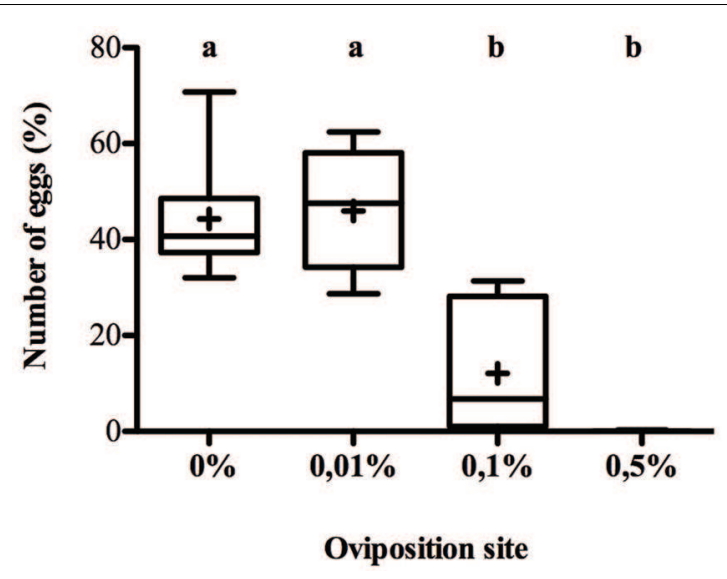

FIGURE 1 | Drosophila melanogaster oviposition preference on menthol-enriched food. Females were given a choice to lay eggs on four sites containing food enriched with $0,0.01,0.1$, or $0.5 \%$ menthol during $12 \mathrm{~h}$. Eggs were then counted for each site and the percentage of eggs in each site is given in the $y$-axis. Data are represented both with their mean (noted by + ) and by box-and-whisker plots (the bars represent the first and third quartiles (Q1 and Q3) with the horizontal band inside the bar indicating the median value; the whiskers indicate the minimum and maximum of all of the data. Different letters indicate a significant difference (Kruskal-Wallis, $K_{4}$ df $=54.76$, $p<0.00001)(N=23)$. 
menthol concentration increased, females displayed a strong aversion and only about $10 \%$ of the eggs were laid in the $0.1 \%$ menthol site whereas females rarely laid eggs on $0.5 \%$ menthol.

\section{Male Discrimination and Courtship Behavior Against Decapitated Females}

In the 10th generation forced-line, when given a choice between $\mathrm{P}$ - and $\mathrm{M}$-line virgin decapitated females, $\mathrm{P}$ - and $\mathrm{M}$-line males courted the females in a similar way $(\mathrm{CIP}=31.07 \pm 4.45$ and $\mathrm{CIM}=25.58 \pm 4.19$ for P-Male; CIP $=23.85 \pm 4.34$ and $\mathrm{CIM}=29.25 \pm 4.26$ for M-Male) (Wilcoxon test, $U=162$, $p=0.500, n=55$ and $U=-170, p=0.428, n=52$ respectively). The same results were obtained with individuals of the 21st generation $(\mathrm{CIP}=33.92 \pm 4.68$ and $\mathrm{CIM}=28.20 \pm 4.45$ for P-Male; $\mathrm{CIP}=25.04 \pm 4.48$ and CIM $=30.71 \pm 4.28$ for M-Male) (Wilcoxon test, $U=144, p=0.502, n=52$ and $U=-167, p=0.423, n=51$ respectively for P-males and M-males (Figure 2A).

In the 10th generation Choice-lines, $\mathrm{P}$-line males courted in a similar manner $\mathrm{P}$ and $\mathrm{M}$-line females $(\mathrm{CIP}=27.69 \pm 4.89$ and $\mathrm{CIM}=23.91 \pm 4.51$ ) (Wilcoxon test, $U=22, p=0.844, n=32$ ). Unlike P-males, M-Line males spent significantly more time courting M-line females than P-line females ( $\mathrm{CIP}=16.85 \pm 4.00$ and CIM $=34.59 \pm 4.96$ ) (Wilcoxon test, $U=-236, p=0.028$, $n=32$ ) (Figure 2B).

\section{Courtship and Mating}

\section{In Forced-Lines}

Males of both $\mathrm{P}$ - and M-lines courted in the same way $\mathrm{P}$ - and M-females (Mann-Whitney test, $p=0.218$ and $p=0.175$ respectively for $\mathrm{P}$-male and $\mathrm{M}$-male). Among the different parameters measured, we only found a significant difference in the latency of mating, M-males mating faster with M-females than with P-females (respectively $771.1 \mathrm{~s} \pm 124.5$ and $1207 \mathrm{~s} \pm 155.5$; MannWhitney test, $p=0.031$ ). Duration of mating and mating success were the same for all the inter-line combinations (Figure 3A).

\section{In Choice-Lines}

P-males displayed a similar intensity of courtship in front of $\mathrm{P}$ and $\mathrm{M}$-females $(\mathrm{CIP}=81.16 \pm 2.68$ and $\mathrm{CIM}=78.18 \pm 5.19$; Mann-Whitney test, $p=0.210)$. Latency and duration of mating were similar in both inter-line combinations (MannWhitney test: $p=0.766$ and $p=0.314$ respectively for mating latency and mating duration) (Figure 3B). However, males of the P-line mated significantly more with P-females than with the M-females (two-tailed Fisher exact test, $p=0.020$ ). M-males courted significantly more $\mathrm{M}$-females than P-females (respectively $\mathrm{CIM}=83.48 \pm 3.92$ and $\mathrm{CIP}=73.42 \pm 5.19$; Mann-Whitney test, $p=0.046)$. Whilst mating latency and duration were the same in front of $\mathrm{P}$ and M-females (MannWhitney test: $p=0.378$ and $p=0.808$ respectively), M-males mated significantly more with the latter (two-tailed Fisher exact test, $p=0.0003$ ).

\section{Influence of Menthol on Female Fecundity}

Females raised on menthol began to lay eggs earlier than those raised on Control and P-food (ANCOVA, $F_{3,236}=916.05$, $p<0.0001$ ) (Figure 4A). They laid an increasing number of eggs during the first days after emergence reaching a maximum at day 4 (mean $=196.4$ eggs \pm 11.69 ), followed by a decrease in day 5 and 6 before increasing again during the last 3 days (Figure 4B). P-line females showed a similar pattern but laid significantly less eggs than M-line females (ANCOVA, $F_{3,236}=28.902$, $p<0.0001)$. Control-line females reached the maximum of eggs laid 2 days later than both choice-lines. After 7 days, the total number of eggs was similar between Control-line and M-line females (Figure 4A). The total number of eggs laid by females after 10 days of experiment was similar for the Control- and the M-Line but was significantly different for the P-Line. Whilst total fecundity was not affected, females of choice-line and particularly $\mathrm{M}$-line females laid eggs precociously compared to control-line females.

\section{Influence of Menthol on Survival Rate in Choice-Lines}

Larvae fully developed into adulthood in a similar way in control media and media supplemented with 0.01 or $0.1 \%$ of menthol $\left(K_{3}\right.$ df $=2.772, p=0.4282$ ) (Figure 5). Menthol at the tested concentrations did not delay nor compromise D. melanogaster development.

\section{DISCUSSION}

\section{Menthol, Courtship and Behavioral Reproductive Isolation}

Courtship behavior in D. melanogaster involves multimodal sensory signals (visual, olfactory, acoustic, and tactile) (Spieth and Ringo, 1983; Yamamoto et al., 1997; O’Dell, 2003). In our study, differences were observed between the forced and the freechoice lines after ten generations. While 'Forced-line' males of both lines courted and mated similarly with $\mathrm{P}$ and $\mathrm{M}$-line females even after 21 generations, showing no ethological reproductive isolation, 'Free-choice line' males mated significantly more with females of their own line. But only choice M-line males were able to discriminate and court more M-females. Like for oviposition, only the choice procedure induced an ethological isolation.

Influence of larval diet on mating preference has been reported in Drosophila species (Dodd, 1989; Etges, 1992; Brazner and Etges, 1993; Pavković-Lucić, 2009; Sharon et al., 2010) with different conclusions. D. pseudoobscura flies showed a reproductive isolation between starch-reared and maltosereared populations (Dodd, 1989). Similarly, an inbred strain of D. melanogaster mated assortatively based on the diet of previous generations ("molasses medium" versus "starch medium”) (Sharon et al., 2010; Najarro et al., 2015). Interestingly, mating preference appeared after only one generation of growth in these different media and lasted for more than 37 generations (Sharon et al., 2010). However Najarro et al. (2015) were 


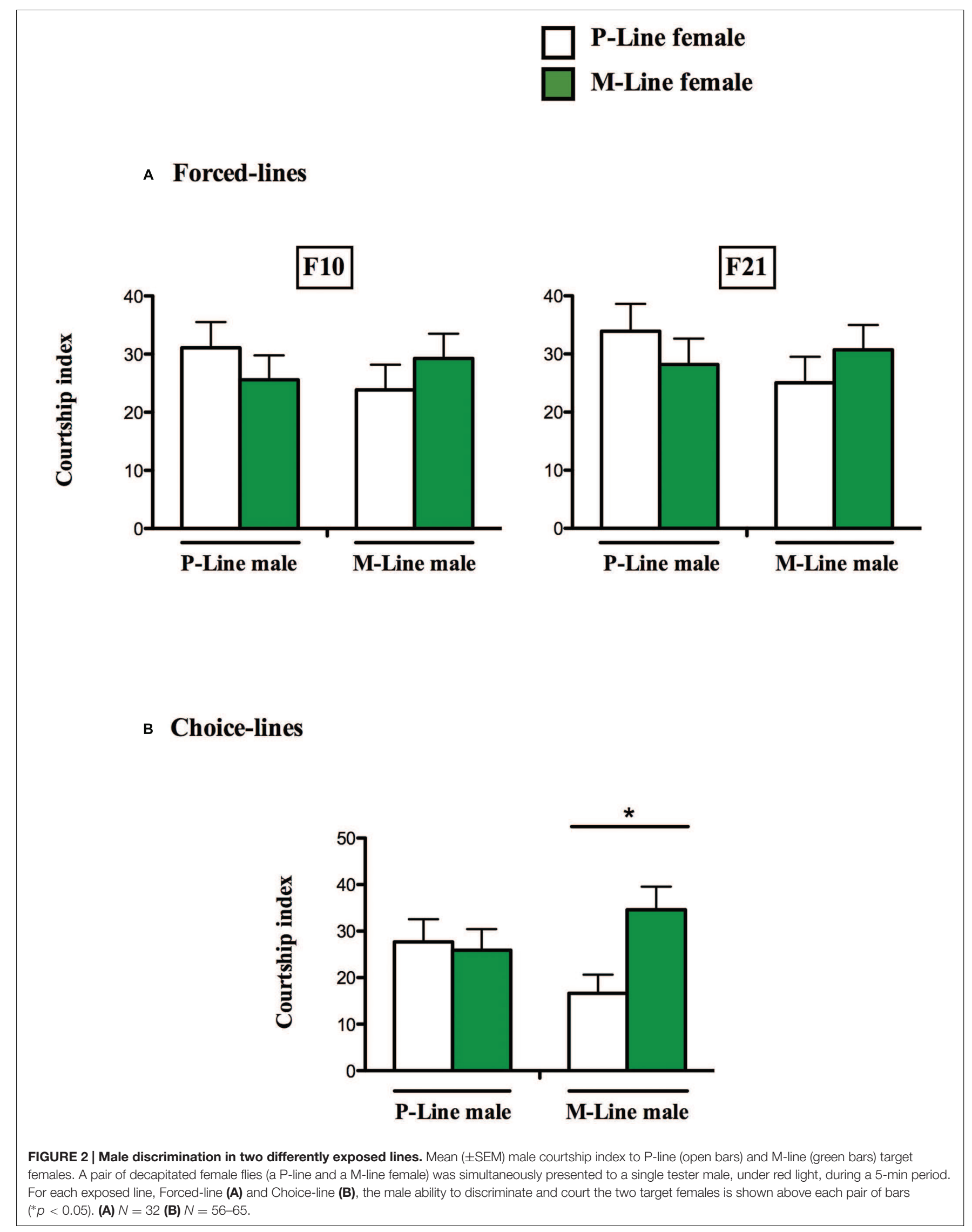




\section{A Forced-Lines}
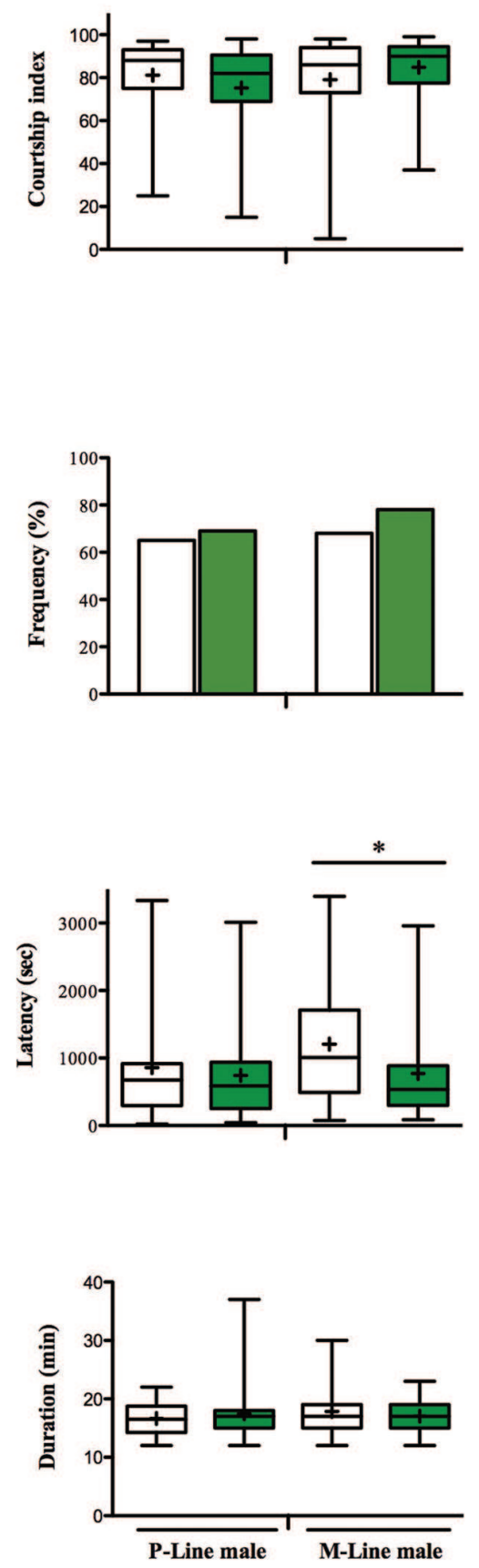

\section{B Choice-Lines}

\section{Courtship}

$\square$ P-Line female

$\square$ M-Line female

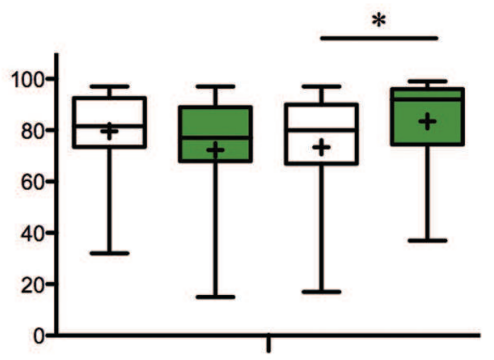

Copulation

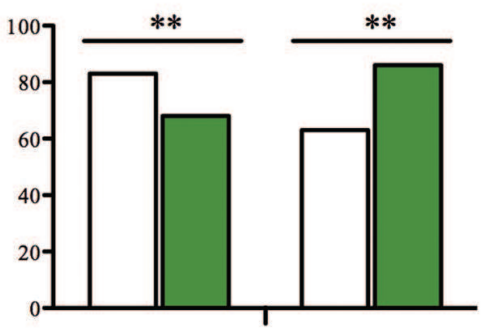

FIGURE 3 | Courtship behavior and mating in two differently exposed lines. Individual 5 day-old males were paired with an intact female of the P-line or the M-line. The box-and-whisker plots show the male courtship index, the latency and the duration of mating. The bar graphs show the frequency of mating. The male courtship index $(\mathrm{Cl})$ to the female is measured for $10 \mathrm{~min}$. The frequency of mating, the copulation latency (copulation onset, in sec) and the copulation duration (in min) were measured for 60 min. P-line females: open bars and open boxes, M-line females: green bars and green boxes. (A) Forced-line, (B) Choice-line $\left({ }^{*} p<0.05\right.$; $\left.{ }^{* *} p<0.01\right)$. (A) $N=12-17$ (B) $N=45-49$. For more information, refer to Figure 1. 


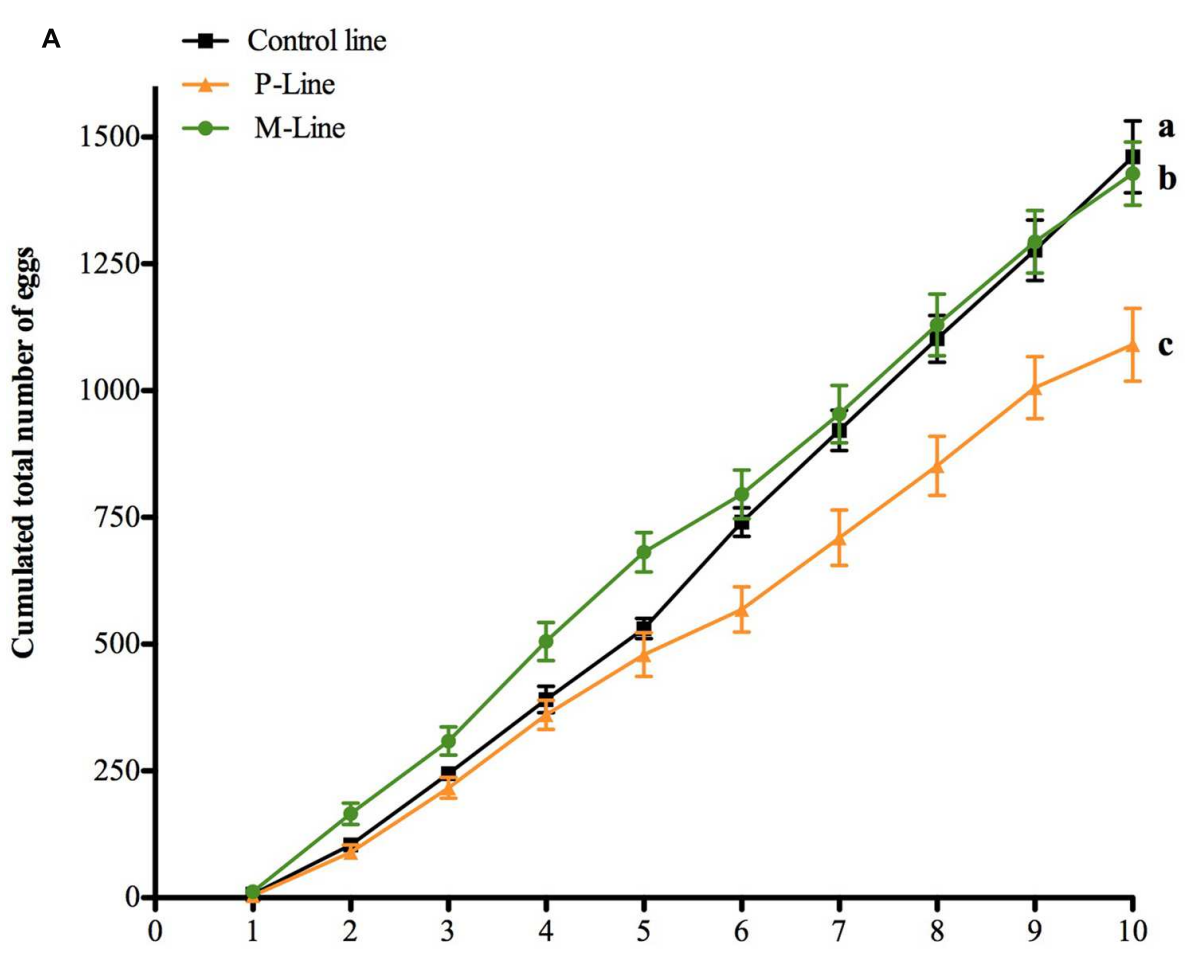

Time (in day)

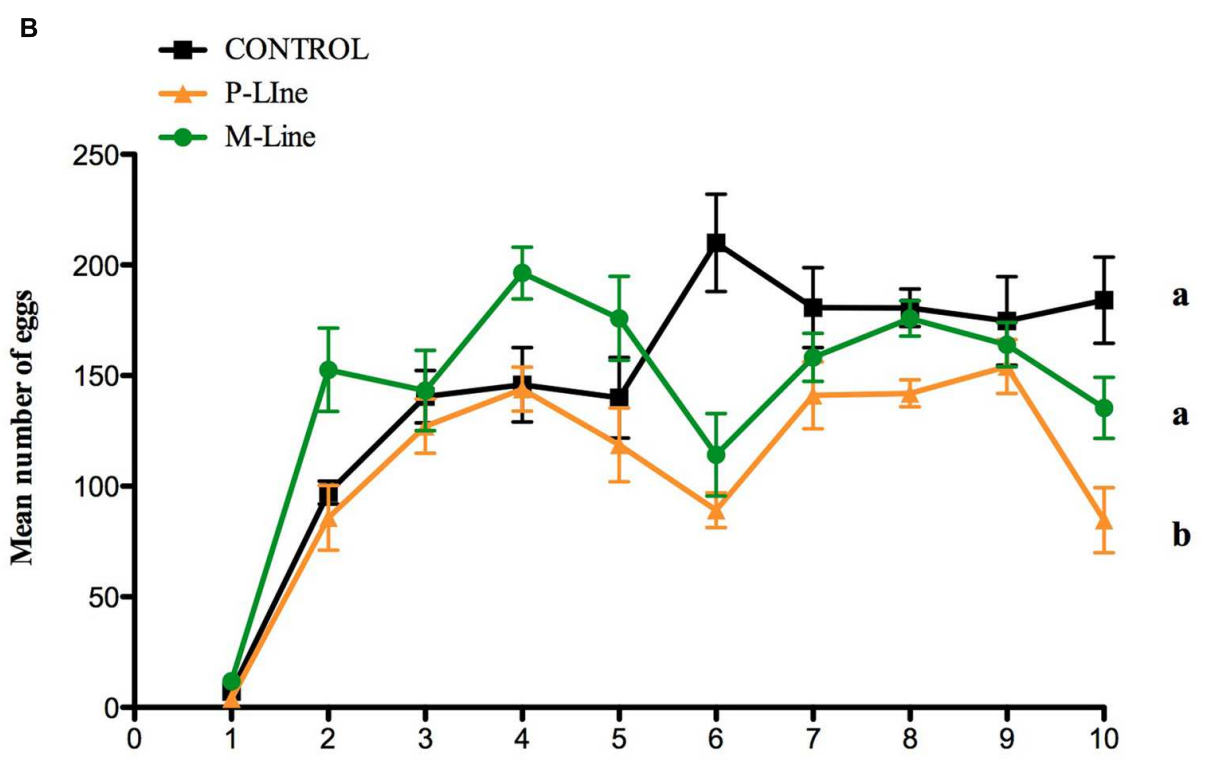

Time (in days)

FIGURE 4 | Fecundity of $\boldsymbol{D}$. melanogaster females during the first 10 days after emergence in an oviposition two-choice test. Control line (C-line) and the two choice-lines ( $\mathrm{P}$ - and M-line) were tested. Mean $( \pm$ SEM) of eggs laid by females of the three lines on two oviposition sites during 10 days after emergence. (A) Cumulated number of eggs and (B) Number of eggs laid daily. Twenty flies (10 females and 10 males) were placed in an arena containing two oviposition sites, one filled with plain-food and one filled with $0.1 \%$ menthol enriched food. Females could lay eggs for a $24 \mathrm{~h}$ period then the two sites were replaced by new ones. The total number of eggs laid on the two sites was counted daily. $N=8$ for each line. Different letters indicate statistical difference [ANCOVA: $F_{3,236}=916.05$, $p<0.0001$ for $(\mathbf{A})$ and, $F_{3,236}=28.902, p<0.0001$ for $\left.(\mathbf{B})\right]$. 


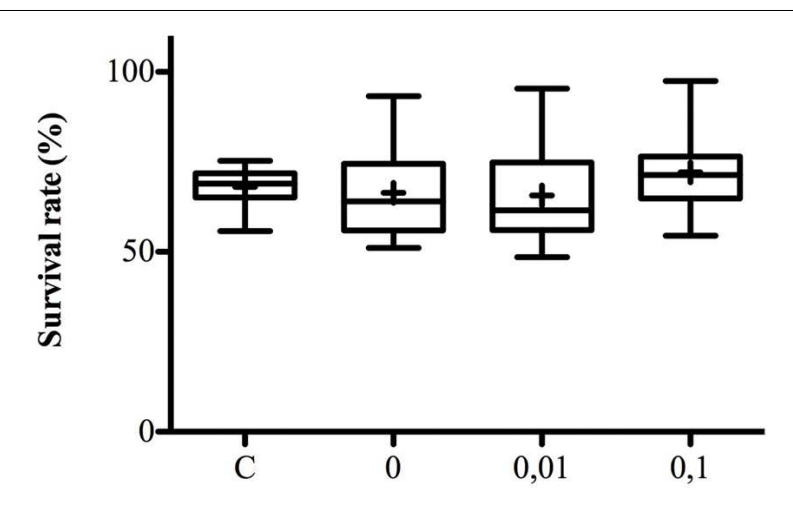

Type of food

FIGURE 5 | Survival rate on control and menthol-enriched food. The box-and-whisker plots show the survival rates on different types of food, C, control food, 0\%, no menthol plain-Food, 0.01, 0.01\% menthol-enriched food, $0.1,0.1 \%$ menthol-enriched food. Females were given the choice to lay eggs on four different oviposition sites with increased menthol concentration ranging from 0 to $0.5 \%$. For each site larvae were raised at $25^{\circ} \mathrm{C}$ until complete development. For Control-line survival rate is measured in a multiple choice assay with four sites filled with control food and flies from parental lines never exposed to menthol. Adults were counted at emergence and survival rate was measured. $N=10-16$. For more information, refer to Figure 1.

unable to generate assortative mating with an outbred strain. When flies were reared or experienced the rearing media in a comparable way as our "forced" lines, no ethological isolation was found (Pavković-Lucić, 2009). The discrepancy between these results is most probably due to the type of medium used. When assortative mating occurred, the strains were raised on different types of food. The microbiome of the two diets were different. No ethological isolation was found when fruit extracts or chemical components (as menthol or ethanol) were added to control food, without changing the type of food. The microbiome was probably not or only slightly affected. When assortative matings occurred, the studies clearly showed the implication of extracellular microbes in this reproductive isolation (Sharon et al., 2010). Cuticular hydrocarbon composition has been shown to change according to diet (Etges et al., 2006; Fedina et al., 2012). The modification on the microbiota led to a modification of the epicuticular hydrocarbon profile of the flies (Sharon et al., 2010).

In our experiment only "Free-choice" M-line males were able to discriminate decapitated or intact females of their own line. Males relied most certainly on chemical cues as our experiments were performed under red light with decapitated females. A GC analysis of female hydrocarbons of both $\mathrm{P}$ - and $\mathrm{M}$-choice lines revealed that $\mathrm{M}$-line females produced significantly more 7,11heptacosadiene, a female specific hydrocarbon, than P-lines females (Supplementary Figure S1). 7,11-heptacosadiene has been reported as the most potent aphrodisiac for males (Antony et al., 1985; Wicker-Thomas, 2007 and reference therein). Although other compounds such as 7,11-nonacosadiene and 7pentacosene play a role in sex recognition, we did not find any difference between the choice-lines. Differences in the amount of 7,11-heptacosadiene in M-line females might explain why
M-males courted more M-females when given the choice between $\mathrm{P}$ and M-females. We cannot exclude that some 'menthol odor' was still present on the flies raised on menthol and that males used this cue for discrimination. However, flies (males and females) were kept in standard medium (without menthol) during the first days of their adult life. Thus, when tested, the amount of menthol adsorbed in the cuticle of flies should be very low. Our GC-analysis setting for hydrocarbons did not allow us to detect or quantify menthol. Several authors reported an extinction of the response to menthol a few hours after having been exposed (Thorpe, 1939; Barron and Corbet, 2000). If so, difference in sensitivity (threshold) may explain the ability of free-choice male to recognize females of their own line, as they were in contact with menthol during their development.

\section{Menthol and Oviposition}

For generalist insect species, such as D. melanogaster, selecting an appropriate oviposition site is essential for progeny survival and fitness. Visual, olfactory and gustatory cues are involved (Renwick and Chew, 1994). In Drosophila, Jaenike (1982) proposed two phases: settling and oviposition. To settle, females use visual and olfactory cues. Before laying eggs, female flies evaluate the composition of the medium through olfactory receptors in the antenna (Dweck et al., 2013) and gustatory receptors present in their proboscis and ovipositor (Yang et al., 2008). Then, concentration of specifics chemicals can induce or prevent oviposition (Depetris-Chauvin et al., 2015). Egglaying preference is primarily relayed through gustatory neurons (Joseph et al., 2009).

When given the choice to lay eggs on menthol-rich food females D. melanogaster showed clear avoidance as concentration increased. This natural repulsive effect has been shown in other Drosophila species (Jaenike, 1982) and most generally in arthropods (Kumar et al., 2011 and reference therein). Preexposure to peppermint or menthol can reduce significantly the aversion (Barron and Corbet, 1999a) and can explain the shift from aversion to indifference for a $0.1 \%$ menthol substrate in the choice M-line females (Abed-Vieillard et al., 2014). Menthol can be perceived through olfactory and gustatory modalities. However, the precise mechanisms for menthol perception in Drosophila remain unclear. No olfactory receptor has yet been identified (Turner and Ray, 2009; Silbering et al., 2011; Münch and Galizia, 2015). In mammals, menthol can activate two transient receptor potential channels: the TRP melastatin-eight TRPM8, which serve as a cold sensor and the TRPA1. But there is no evidence of such a function in Drosophila TRPM8 (Fowler and Montell, 2013; Saito and Tominaga, 2015, for review) and TRPA1 is insensitive to menthol in non-mammalian species (Xiao et al., 2008). In D. melanogaster, thermotaxis response to cool temperatures requires the function of the TRP and TRPL channels (Bellemer, 2015 for review). Besides serving as a cold sensor, TRPL is involved in gustatory responses. It is involved in detection of aversive compounds and is expressed in bitter neurons in the labellum (Zhang et al., 2013). Menthol has been reported to inhibit the TRPL channel (Parnas et al., 2009). As for camphor (Zhang et al., 2013), it is possible that long term feeding on menthol can affect TRPL protein levels, making a menthol 
rich-medium more acceptable for feeding and oviposition in the M-choice line. A limited number of olfactory pathways seem to be involved in oviposition site selection and female preference can be mediated via only a single olfactory channel in several Drosophila species (Dekker et al., 2006; Yang et al., 2008; Herrero, 2012; Dweck et al., 2013; Linz et al., 2013; Keesey et al., 2015).

\section{Menthol and Fecundity}

According to the preference-performance hypothesis, females should choose the site were their offspring fare best. A $0.1 \%$ menthol concentration did not impair larval development and adult survival, but a $0.15 \%$ concentration reduced fly survival (Barron and Corbet, 1999b). Food supplemented with 0.05\% of peppermint is lethal for $D$. recens adults (Jaenike, 1982) and high concentration (more than $0.5 \%$ ) of peppermint oil is toxic for D. melanogaster larva (Thorpe, 1939). Here we showed that a $0.1 \%$ menthol concentration did not impair Drosophila development and that females of the Choice M-line laid eggs earlier than Control-line females. These results are consistent with a previous study (Abed-Vieillard et al., 2014) where females of the Choice-line were only tested for oviposition from day 1 to day 5 after hatching. Here we show that the increased number of eggs during the first days of adult life was not due to an increase in female fecundity but to precocious egg laying. However, we cannot exclude that this phenomenon may be due to menthol-induced hastened female maturity or oogenesis.

The genetic basis for oviposition site preference and the decision to oviposit has been investigated in $D$. melanogaster for many years and several studies have confirmed the genetic plasticity of this behavior (Takamura and Fuyama, 1980; Allemand and Boulétreau-Merle, 1989; Yang et al., 2008; Miller et al., 2011). D. melanogaster is a generalist insect, keeping a broad possibility to feed, lay eggs and develop. Even after being reared for decades in laboratories, the species still displays oviposition behavioral plasticity that can account for its worldwide distribution. Females did not change their oviposition preference even after being 'forcibly' raised on a particular medium for many generations (Abed-Vieillard et al., 2014; Soto et al., 2014). However, in several studies, D. melanogaster rapidly responded to selection for oviposition site preference

\section{REFERENCES}

Abed-Vieillard, D., Cortot, J., Everaerts, C., and Ferveur, J. F. (2014). Choice alters Drosophila oviposition site preference on menthol. Biol. Open 3, 22-28. doi: 10.1242/bio. 20136973

Allemand, R., and Boulétreau-Merle, J. (1989). Correlated responses in lines of Drosophila melanogaster selected for different oviposition behaviours. Experientia 15, 1147-1150. doi: 10.1007/BF01950184

Antony, C., Davis, T. L., Carlson, D. A., Pechine, J. M., and Jallon, J. M. (1985). Compared behavioral responses of male Drosophila melanogaster (CantonS) to natural and synthetic aphrodisiacs. J. Chem. Ecol. 11, 1617-1629. doi: 10.1007/BF01012116

Atkinson, W. D., and Shorrocks, B. (1977). Breeding site specificity in the domestic species of Drosophila. Oecologia 29, 223-232. doi: 10.1007/BF00345697

Barron, A. B., and Corbet, S. A. (1999a). Pre-exposure affects the olfactory response of Drosophila melanogaster to menthol. Entomol. Exp. Appl. 90, 175-181. doi: 10.1046/j.1570-7458.1999.00436.x
(Markow and O'Grady, 2008 and references therein). Since divergent results were obtained in menthol "forced" line and "free-choice" lines for oviposition and mating, choosing freely the egg-laying sites (as in natural populations) appeared to induce faster changes. Neural pathways underlying the change of oviposition response are under investigation (Joseph and Heberlein, 2012; Zhang et al., 2013). We did not explain why "forced" lines respond differently than the "choice" line to a long term-exposition to menthol. It seems that the possibility of choice decision makes the difference (Brembs, 2011). Further investigations on mechanisms of menthol perception and on the neural pathway involved in the behavioral change induced by menthol in the choice procedure will be of interest.

\section{AUTHOR CONTRIBUTIONS}

DA-V and JC performed the experiments; DA-V analyzed the data and wrote the paper.

\section{FUNDING}

This work was supported in part by the Centre National de la Recherche Scientifique [PICS 4425], the Burgundy Regional Council (PARI), and the French Ministry of Research and Higher Education.

\section{ACKNOWLEDGMENTS}

We thank Serge Loquin and José Solonot for technical help, and Claude Everaerts for the statistics.

\section{SUPPLEMENTARY MATERIAL}

The Supplementary Material for this article can be found online at: http://journal.frontiersin.org/article/10.3389/fnint. 2016.00005

Barron, A. B., and Corbet, S. A. (1999b). Preimaginal conditioning in Drosophila revisited. Anim. Behav. 58, 621-628. doi: 10.1016/anbe.1999.1169

Barron, A. B., and Corbet, S. A. (2000). Behavioural induction in Drosophila: timing and specificity. Entomol. Exp. Appl. 94, 159-171. doi: 10.1046/j.15707458.2000.00616.x

Battesti, M., Moreno, C., Joly, D., and Mery, F. (2015). Biased social transmission in Drosophila oviposition choice. Behav. Ecol. Sociobiol. 69, 83-87. doi: 10.1007/s00265-014-1820-x

Bellemer, A. (2015). Thermotaxis, circadian rhythms, and TRP channels in Drosophila. Temperature 2, 227-243. doi: 10.1080/23328940.2015.1004972

Bentley, M. D., and Day, J. F. (1989). Chemical ecology and behavioral aspects of mosquito oviposition. Annu. Rev. Entomol. 34, 401-421. doi: 10.1146/annurev.en.34.010189.002153

Brazner, J. C., and Etges, W. J. (1993). Pre-mating isolation is determined by larval rearing substrates in cactophilic Drosophila mojavensis. II Effects of larval substrates on time to copulation, mate choice and mating propensity. Evol. Ecol. 7, 605-624. doi: 10.1007/BF01237824 
Brembs, B. (2011). Towards a scientific concept of free will as a biological trait: spontaneous actions and decision-making in invertebrates. Proc. R. Soc. Lond. B 278, 930-939. doi: 10.1098/rspb.2010.2325

Coyne, J. A., and Orr, H. A. (2004). Speciation. Sunderland, MA: Sinauer Associates, Inc.

Dekker, T., Ibba, I., Siju, K. P., Stensmyr, M. C., and Hansson, B. S. (2006). Olfactory shifts parallel superspecialism for toxic fruit in Drosophila melanogaster sibling, D. sechellia. Curr. Biol. 16, 101-109. doi: 10.1016/j.cub.2005. 11.075

Depetris-Chauvin, A., Galagovsky, D., and Grosjean, Y. (2015). Chemicals and chemoreceptors: ecologically relevant signals driving behavior in Drosophila. Front. Ecol. Evol. 3:41. doi: 10.3389/fevo.2015.00041

Dodd, D. M. B. (1989). Reproductive isolation as a consequence of adaptive divergence in Drosophila pseudoobscura. Evolution 43, 1308-1311. doi: $10.2307 / 2409365$

Dweck, H. K. M., Ebrahim, S. A. M., Kromann, S., Bown, D., Hillbur, Y., Sachse, S., et al. (2013). Olfactory preference for egg laying on citrus substrates in Drosophila. Curr. Biol. 23, 2472-2480. doi: 10.1016/j.cub.2013.10.047

Etges, W. J. (1990). "Direction of life history evolution in Drosophila mojavensis," in Ecological and Evolutionary genetics of Drosophila, eds J. S. F. Barker, W. T. Starmer, and R. J. Macintyre (New York, NY: Springer), 37-56. doi: 10.1007/978-1-4684-8768-8_4

Etges, W. J. (1992). Premating isolation is determined by larval substrates in cactophilic Drosophila mojavensis. Evolution 46, 1945-1950. doi: $10.1111 /$ jeb. 12073

Etges, W. J., Veenstra, C. L., and Jackson, L. L. (2006). Premating isolation is determined by larval rearing substrates in cactophilic Drosophila mojavensis. VII. Effects of larval dietary fatty acids on adult epicuticular hydrocarbons. J. Chem. Ecol. 32, 2629-2646. doi: 10.1007/s10886-006-9187-8

Feder, J. L., Opp, S. B., Wlazlo, B., Reynolds, K., Go, W., and Spisak, S. (1994). Host fidelity is an effective premating barrier between sympatric races of the apple maggot fly. Proc. Natl. Acad. Sci. U.S.A. 91, 7990-7994. doi: 10.1073/pnas.91.17.7990

Fedina, T. Y., Kuo, T. H., Dreisewerd, K., Dierick, H. A., Yew, J. Y., and Pletcher, S. D. (2012). Dietary effects on cuticular hydrocarbons and sexual attractiveness in Drosophila. PLoS ONE 7:e49799. doi: 10.1371/journal.pone.0049799

Flaven-Pouchon, J., Garcia, T., Abed-Vieillard, D., Farine, J. P., Ferveur, J. F., and Everaerts, C. (2014). Transient and permanent experience with fatty acids changes Drosophila melanogaster preference and fitness. PLoS ONE 9:e92352. doi: 10.1371/journal.pone.0092352

Fogleman, J. C. (1979). Oviposition site preference for substrate temperature in Drosophila melanogaster. Behav. Genet. 9, 407-412. doi: 10.1007/BF010 66978

Fowler, M. A., and Montell, C. (2013). Drosophila TRP channels and animal behavior. Life Sci. 92, 394-403. doi: 10.1016/j.lfs.2012.07.029

Gilbert, D. G., and Starmer, W. T. (1985). Statistics of sexual isolation. Evolution 39, 1380-1383. doi: 10.2307/2408793

Herrero, P. (2012). Fruit fly behavior in response to chemosensory signals. Peptides 38, 228-237. doi: 10.1016/j.peptides.2012.09.019

Houot, B., Bousquet, F., and Ferveur, J. F. (2010). The consequences of regulation of desat1 expression for pheromone emission and detection in Drosophila melanogaster. Genetics 185, 1297-1309. doi: 10.1534/genetics.110.117226

Jaenike, J. (1982). Environmental modification of oviposition behavior in Drosophila. Am. Nat. 119, 784-802. doi: 10.1086/283955

Jaenike, J. (1983). Induction of host preference in Drosophila melanogaster. Oecologia 58, 320-325. doi: 10.1371/journal.pone.0105444

Jaenike, J. (1986). Genetic complexity oh host selection behavior in Drosophila. P. Natl. Acad. Sci. U.S.A. 86, 2148-2151. doi: 10.1073/pnas.83. 7.2148

Joseph, R. M., Devineni, A. V., King, I. F. G., and Heberlein, U. (2009). Oviposition preference for and positional avoidance of acetic acid provide a model for competing behavioral drives in Drosophila. Proc. Natl. Acad. Sci. U.S.A. 106, 11352-11357. doi: 10.1073/pnas.0901419106

Joseph, R. M., and Heberlein, U. (2012). Tissue-specific activation of a single gustatory receptor produces opposing behavioral responses in Drosophila. Genetics 192, 521-532. doi: 10.1534/genetics.112.142455

Keesey, I. W., Knaden, M., and Hansson, B. S. (2015). Olfactory specialization in Drosophila suzukii supports an ecological shift in host preference from rotten to fresh fruit. J. Chem. Ecol. 41, 121-128. doi: 10.1007/s10886-0150544-3

Kumar, P., Mishra, S., and Malik, A. (2011). Insecticidal properties of Mentha species: a review. Ind. Crops Prod. 34, 802-817. doi: 10.1016/j.indcrop.2011.02.019

Linz, J., Baschwitz, A., Strutz, A., Dweck, H. K. M., Sachse, S., Hansson, B. S., et al. (2013). Host plant-driven sensory specialization in Drosophila erecta. Proc. $R$. Soc. Lond. B 280, 1-9. doi: 10.1098/rspb.2013.0626

Markow, T. A., and O'Grady, P. M. (2008). Reproductive ecology of Drosophila. Funct. Ecol. 22, 747-759. doi: 10.1111/j.1365-2435.2008.01457.x

Matsubayashi, K. W., Ohshima, I., and Nosil, P. (2010). Ecological speciation in phytophagous insects. Entomol. Exp. Appl. 134, 1-27. doi: 10.1111/j.15707458.2009.00916.x

Miller, P. M., Saltz, J. B., Cochrane, V. A., Marcinkowski, C. M., Mobin, R., and Turner, T. L. (2011). Natural variation in decisionmaking behavior in Drosophila melanogaster. PLoS ONE 6:e16436. doi: 10.1371/journal.pone.0016436

Minkenberg, O. P. J. M., Tatar, M., and Rosenheim, J. A. (1992). Egg Load as a major source of variability in insect foraging and oviposition behavior. Oikos 65, 134-142. doi: 10.2307/3544896

Mokany, A., and Shine, R. (2003). Oviposition site selection by mosquitoes is affected by cues from conspecific larvae and anuran tadpoles. Austral Ecol. 28, 33-37. doi: 10.1046/j.1442-9993.2003.01239.x

Münch, D., and Galizia, C. G. (2015). DoOR 2.0 - Comprehensive mapping of Drosophila melanogaster odorant responses. bioRxiv doi: 10.1101/027920

Najarro, M. A., Sumethasorn, M., Lamoureux, A., and Turner, T. L. (2015). Choosing mates based on the diet of your ancestors: replication of nongenetic assortative mating in Drosophila melanogaster. Peer J. 3:e1173. doi: $10.7717 /$ peerj. 1173

O'Dell, K. (2003). The voyeurs' guide to Drosophila melanogaster courtship. Behav. Process. 64, 211-223. doi: 10.1016/S0376-6357(03)00136-0

Papaj, D. R., and Prokopy, R. J. (1989). Ecological and evolutionary aspects of learning in phytophagous insects. Annu. Rev. Entomol. 34, 315-350. doi: 10.1146/annurev.en.34.010189.001531

Parnas, M., Peters, M., Dadon, D., Lev, S., Vertkin, I., Slutsky, I., et al. (2009). Carvacrol is a novel inhibitor of Drosophila TRPL channel and mammalian TRPM7 channels. Cell Calcium 45, 300-309. doi: 10.1016/j.ceca2008.1 1.009

Pavković-Lucić, S. (2009). Is there ethological isolation among Drosophila melanogaster strains reared for more than 35 generations on different food ? Arch. Biol. Sci. 61, 105-112. doi: 10.2298/ABS0901105P

Renwick, J. A. A., and Chew, F. S. (1994). Oviposition behavior in Lepidoptera. Annu. Rev. Entomol. 39, 377-400. doi: 10.1146/annurev.en.39.010194. 002113

Saito, S., and Tominaga, M. (2015). Functional diversity and evolutionary dynamics of thermoTRP channels. Cell Calcium 57, 214-221. doi: 10.1016/j.ceca.2014.12.001

Sarin, S., and Dukas, R. (2009). Social learning about egg-laying substrates in fruitflies. Proc. R. Soc. Lond. B 276, 4323-4328. doi: 10.1098/rspb.2009 .1294

Sharon, G., Segal, D., Ringo, J. M., Hefetz, A., Zilber-Rosenberg, I., and Rosenberg, E. (2010). Commensal bacteria play a role in mating preference of Drosophila melanogaster. Proc. Natl. Acad. Sci. U.S.A. 107, 20051-20056. doi: 10.1073/pnas.1009906107

Silbering, A. F., Rytz, R., Grosjean, Y., Abuin, L., Ramdya, P., Jefferis, G. S., et al. (2011). Complementary function and integrated wiring of the evolutionarily distinct Drosophila Olfactory subsystems. J. Neurosci. 31, 13357-13375. doi: 10.1523/JNEUROSCI.2360-11.2011

Soto, E. M., Betti, M. I. L., Hurtado, J., and Hasson, E. (2014). Differential responses to artificial selection on oviposition site preferences in Drosophila melanogaster and D. simulans. Insect Sci. 22, 1-8. doi: 10.1111/1744-7917.12176

Spieth, H. T., and Ringo, J. M. (1983). "Mating behavior and sexual isolation in Drosophila," in The Genetics and Biology of Drosophila, Vol. 3c, eds M. Ashburner and H. J. T. Carson (Cambridge, MA: Academic Press), 223-284.

Takamura, T., and Fuyama, Y. (1980). Behaviour genetics of choice of oviposition sites in Drosophila melanogaster. I. Genetic variability and analysis of behavior. Behav. Genetics 10, 105-120. doi: 10.1007/BF01067322 
Thorpe, W. H. (1939). Further studies on pre-imaginal olfactory conditioning in insects. Proc. Roy. Soc. Lond. B Biol. Sci. 127, 424-433. doi: 10.1098/rspb.1939.0032

Turner, S. L., and Ray, A. (2009). Modification of $\mathrm{CO}_{2}$ avoidance behaviour in Drosophila by inhibitory odorants. Nature 461, 277-281. doi: 10.1038/nature08295

Volpe, P., Carfagna, M., and Di Lorenzo, M. (1967). Extraretinal pigmentation and colour discrimination. I. Choice of colour of substrate in Drosophila melanogaster. J. Exp. Biol. 47, 297-305.

Wicker-Thomas, C. (2007). Pheromonal communication involved in courtship behavior in Diptera. J. Insect Physiol. 53, 1089-1100. doi: 10.1016/j.jinsphys.2007.07.003

Xiao, B., Dubin, A. E., Bursulaya, B., Viswanath, V., Jegla, T. J., and Patapoutian, A. (2008). Identification of Transmembrane domain 5 as a critical molecular determinant of menthol sensitivity in mammalian TRPA1 channels. J. Neurosci. 28, 9640-9651. doi: 10.1523/JNEUROSCI.2772-08.2008

Yamamoto, D., Jallon, J. M., and Komatsu, A. (1997). Genetic dissection of sexual behavior in Drosophila melanogaster. Annu. Rev. Entomol. 42, 551-585. doi: 10.1146/annurev.ento.42.1.551
Yang, C. H., Belawat, P., Hafen, E., Jan, L. Y., and Jan, Y. N. (2008). Drosophila egg laying site selection as a system to study simple decisionmaking processes. Science 319, 1679-1683. doi: 10.1126/science.1 151842

Zhang, Y. V., Raghuwanshi, R. P., Shen, W. L., and Montell, C. (2013). Food experience-induced taste desensitization modulated by the Drosophila TRPL channel. Nat. Neurosci. 16, 1468-1476. doi: 10.1038/n n.3513

Conflict of Interest Statement: The authors declare that the research was conducted in the absence of any commercial or financial relationships that could be construed as a potential conflict of interest.

Copyright (c) 2016 Abed-Vieillard and Cortot. This is an open-access article distributed under the terms of the Creative Commons Attribution License (CC BY). The use, distribution or reproduction in other forums is permitted, provided the original author(s) or licensor are credited and that the original publication in this journal is cited, in accordance with accepted academic practice. No use, distribution or reproduction is permitted which does not comply with these terms. 